\title{
Fine Distributed Moderating Material with Improved Thermal Stability Applied to Enhance the Feedback Effects in SFR Cores
}

\author{
Bruno Merk \\ Department of Reactor Safety, Institute of Resource Ecology, Helmholtz-Zentrum Dresden-Rossendorf, P.O. Box 5101 19, \\ 01314 Dresden, Germany
}

Correspondence should be addressed to Bruno Merk; b.merk@hzdr.de

Received 16 July 2013; Revised 29 August 2013; Accepted 4 September 2013

Academic Editor: Konstantin Mikityuk

Copyright (C) 2013 Bruno Merk. This is an open access article distributed under the Creative Commons Attribution License, which permits unrestricted use, distribution, and reproduction in any medium, provided the original work is properly cited.

The use of fine distributed moderating material to enhance the feedback effects and to reduce the sodium void effect in sodiumcooled fast reactor cores is described. The influence of the moderating material on the fuel assembly geometry, the neutron spectrum, the feedback effects, the power and burnup distribution, and the transmutation performance is given. An overview on possible materials is provided and the relationship between hydrogen content and thermal stability is described. A solution for the problem of the limited thermal stability of primarily proposed hydrogen-bearing moderating material $\mathrm{ZrH}_{1.6}$ is developed by the use of yttrium-mono-hydride. The similarity in the effects reached by $\mathrm{ZrH}$ and $\mathrm{YH}$ is demonstrated by comparison calculations. The topic is closed by an overview on material properties, manufacturing issues, experience in fast reactors, and a comparison of raw material costs.

\section{Introduction}

The positive coolant density feedback coefficient is inherent to the system in sodium-cooled fast reactors (SFRs), and the fuel temperature feedback is comparably low. Both facts are important boundary conditions for the design of future sodium-cooled fast reactors. The relevance of the topic has been highlighted in the last year in the IAEA TM on Innovative Fast Reactor Designs with Enhanced Negative Reactivity Feedback Features in Vienna [1]. The positive coolant density effect is additionally the basis for the sodium void effect, which is the maximal reduction of the sodium density. The reduction of the sodium void effect as well as the enhancement of the negative feedback effects is an important point in the design of sodium-cooled fast reactors. The feedback effects in fast reactors as well as the sodium void effect itself and the different contributions to the effect are well known since the 1960s. Detailed descriptions have already been given in "Reactivity Coefficients in Large Fast Power Reactors" in 1970 [1]. Already in the 1970s numerical studies were conducted with the aim to reduce the sodium void effect [2]. These studies were mostly based on full core calculations for the optimization of the core geometry to reduce the sodium void effect by increasing the leakage component. One important outcome of these full core studies is the development of high leakage cores with their big core diameter ( $\sim 5$ meters) in combination with a very small core height ( $\leq 1$ meter). Current publications mostly concentrate on the design of sodium-cooled fast reactor cores [3] and basic or detailed discussions on the different influencing parameters on the sodium void coefficient $[4,5]$ and the limited possibilities for enhancing the feedback effects in traditional designs. Studies concentrating on the reduction of the sodium void effect have been performed in the framework of CP-ESFR project of the European commission by several institutions [5-7].

In recent times, a new design proposal for the old idea of introducing moderating material has been given. The positive void effect is here reduced in combination with a significant increase of the absolute value of the fuel temperature effect (Doppler effect) and a decrease of the positive coolant effect by adding fine distributed moderating material. The study has been focused in the first step on the choice of the ideal moderating material $[8,9]$ and in a second step on the optimization of the placing of the applied zirconium hydride inside the fuel assembly to obtain the optimal effect in power distribution 
and burnup as well as during transients $[10,11]$. In the third step the focus has been put on the influence of the moderating material on the transmutation performance of a SFR $[12,13]$. It is shown that the insertion of fine distributed material has nearly no influence on the transmutation performance itself, but it opens the possibility to increase the minor actinide amount due to the compensation of the effects of minor actinides on the feedback coefficients. Up to this point, a major limitation and a point of critics in several reviews were the use of $\mathrm{ZrH}$-based moderators, since the thermal stability cannot be reliably assured up to the temperature of the onset of sodium voiding; dissociation rises sharply around $880^{\circ} \mathrm{C}$ and sodium voiding starts around $883^{\circ} \mathrm{C}$. Thus the dissociation cannot be avoided safely during a transient and the dissociation followed by a loss of hydrogen would definitively worsen the transient. A first glace to solve the problem of thermal stability of the moderating material is given in $[12,14]$. It is indicated that a change of the metal component of the metal hydrogen compound has significant potential to increase the thermal stability of the moderating material at higher temperatures.

The calculations for all studies are performed with the lattice transport code HELIOS and based detailed full fuel assembly geometry representation. These possibilities are given due to the rapid development of the spectral codes for LWR analysis which solve the integral transport equation in two dimensions on unstructured mesh $[15,16]$. These codes offer the chance to investigate the feedback effects on fuel assembly level for different designs in full detail including multigroup visualization of integral and resolved neutron flux and cross-sections. Besides HELIOS, the Monte-Carlo code MCNP has been used for the verification of the general results for the introduction of fine distributed moderating material (see $[8,9])$ in an in infinite grid, and the nodal core simulator DYN3d has been used for the confirmation of the transferability of the findings to a finite system (see [9]).

In this study a comprehensive investigation for the identification of a moderating material with increased thermal stability is performed. First an overview is given on a number of possible materials and the relationship between hydrogen content and thermal stability is described. Using this information a decision for the most appropriate material is taken. In a next step an overview on material properties, manufacturing issues, experience in fast reactors, and a comparison of raw material costs is given. Following this paper study, the material choice is confirmed by calculations for the effect of the new moderating material which will be compared to the results obtained for $\mathrm{ZrH}$ material.

\section{Reference Configuration}

The study is based on a reference case derived from data for the European Fast Reactor (EFR). The EFR core has been designed as iso breeder. The core itself has converter configuration; thus, the Pu content is decreased. The decrease is compensated by the breeding in the blankets [17]. The data for the core configuration is mostly given in the IAEA Fast Reactor Database-2006 Update [17]. Additional data is

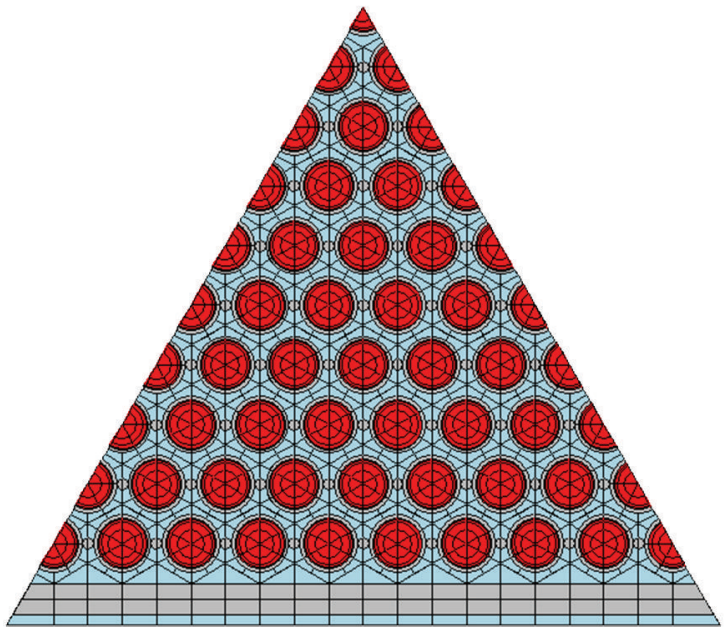

FIGURE 1: 1/6 of the reference fuel assembly geometry corresponding to the EFR geometry.

taken from Waltar and Reynolds: Fast Breeder Reactors [18] and from European fast reactor fuel assembly design [19]. The following major parameters are used for the reference calculation.

\section{Outer pin diameter $8.5 \mathrm{~mm}$. \\ Cladding thickness $0.52 \mathrm{~mm}$.}

Pitch to diameter 1.2.

Can wall thickness $4.5 \mathrm{~mm}$.

Fuel rods per assembly 271.

MOX fuel with 22.4\% Pu fissile (intermediate core region in EFR) and a Pu vector from 4\% enriched UOX fuel with $50 \mathrm{GWd} / \mathrm{tHM}$ burnup is used. Five-year storage before reprocessing and 2 years until reuse in the reactor are supposed (Pu-238, 2.63\%; Pu-239, 54.43\%; Pu-240, 23.70\%; Pu-241, 11.28\%; $\mathrm{Pu}-242$, 6.83\%; Am-241, 1.14\%). The $\mathrm{Pu}$ is mixed in depleted uranium with smeared fuel density $9.26 \mathrm{~g} / \mathrm{cm}^{3}$ and $900^{\circ} \mathrm{C}$ fuel temperature.

Cladding, wire wrapper, and can wall made from stainless steel 304 along the HELIOS 1.9 definition. Temperature of $635^{\circ} \mathrm{C}$ for the cladding and $545^{\circ} \mathrm{C}$ for wrapper and can wall are used. A sodium density $0.821 \mathrm{~g} / \mathrm{cm}^{3}$ along the formula for liquid-saturated sodium at $545^{\circ} \mathrm{C}$ given in Waltar and Reynolds [18] is used.

The modeled geometric arrangement of the reference system with 10 rings, following the EFR design, is shown in Figure 1 for a $1 / 6$ part of one fuel assembly. The specific power is set to $118.8 \mathrm{~W} / \mathrm{g}$ corresponding to the maximum power density in the EFR. The HELIOS 1.9 internal 112 group fast reactor library is used for the calculations [20].

The applied code HELIOS 1.9 is mostly used for light water reactor calculations. For validation of the very significant results caused by the insertion of moderating material on the feedback coefficients, a cross-comparison with MCNP for the initial value of fuel temperature and moderator effect on $k_{\text {inf }}$ was performed on a simplified basis at the beginning 


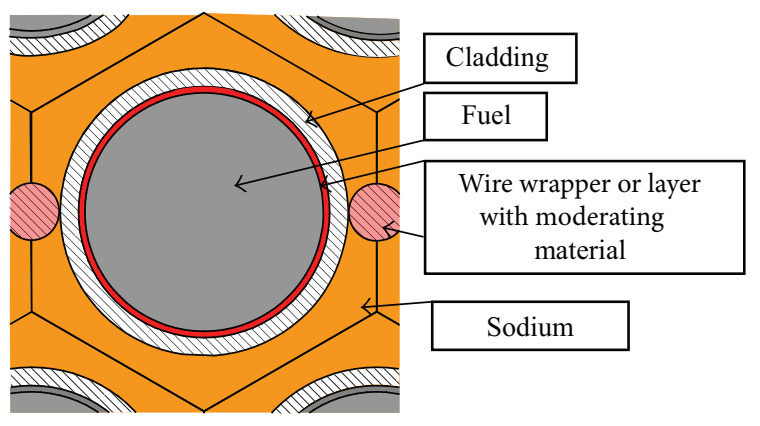

FIGURE 2: Unit cell out of a fuel assembly based on the European fast reactor (EFR) design with introduced moderation layer.

of the project. Very good agreement has been achieved for both effects $[8,9]$. In further comparisons with the SERPENT Monte-Carlo-based codes with burnup capabilities good agreement was found for the burnup of actinides and minor actinides in fast reactor configurations. The good agreement is given for the use of the 112 and 190 group HELIOS 1.10 libraries and could even be improved using the new 177 group library of HELIOS 2 which was not available at the beginning of the study [21]. This good agreement to continuous energy methods gives confidence in the applicability of the code HELIOS, the methods applied inside the code, and the results for steady state as well as for the burnup calculations. Finally, it has to be kept in mind that the analysis is based on the changes caused by slight material changes; thus, the final absolute amounts are not the major information, but the relative differences between the calculated configurations.

\section{System with Moderating Material}

The general idea to shift a small portion of the neutron spectrum to lower energies is achieved by introducing fine distributed moderating material-hydrogen-into the reactor core. This concept has already been presented in several journal papers and at several conferences. For the basic understanding, a short overview will be given in the following chapter. The most convenient position is inside the wire wrapper or in a form of a thin layer inside the cladding as shown in Figure 2. For the visualization purpose, only one hexagonal unit cell is extracted from the calculated $1 / 6$ of a full fuel assembly given in Figure 1. The single purpose of the introduced fine distributed moderating material is to force up the absolute value of the negative fuel temperature feedback effect (Doppler effect) and to reduce the positive coolant feedback effect (consisting of coolant density and temperature effect) coinciding with a strong reduction of the positive sodium void effect. The fine distribution of the moderating material in the fast reactor fuel assembly which is achieved by introducing the material into each unit cell. This method offers the possibility to keep the original fuel assembly geometry and design as well as the high power density and the characteristic uniform power distribution typical for a fast reactor fuel assembly. These three facts ensure that the coolant flow rate and distribution in the

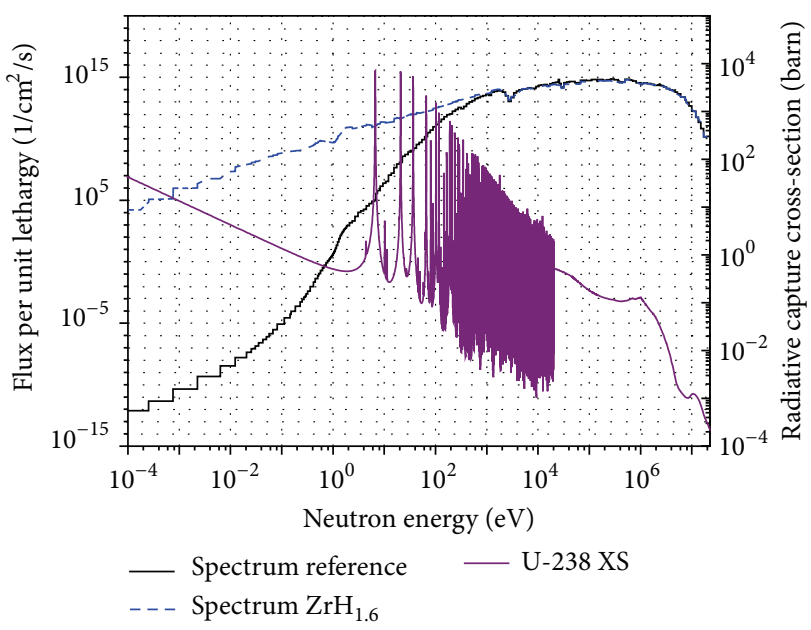

FIGURE 3: Neutron spectrum for the reference fuel assembly and for the fuel assembly with moderating material calculated with the 190 group library of HELIOS 1.9 and compared to the radiative capture cross-section of uranium-238.

fuel assembly can be kept as proposed in the reference design. Thus the whole coolant flow path and volume can be optimized independently and in an unchanged matter compared to the core without moderating material to ensure or improve the safety-related coolability. The moderating material for the general investigation has been $\mathrm{ZrH}_{1.6}$ [8-10] which can be used as wire wrapper itself or as layer inside the cladding. Since thermal stability of the moderating material during a postulated transient is of paramount importance for the safety of the system, the possible improvement of the thermal stability will be analyzed in this publication after the general overview on the possibilities of the introduction of fine distributed material.

The exact location of the wire wrapper is not fixed in the real fuel assembly of a fast reactor core. This fact can cause some uncertainty, but earlier studies have shown that the most important fact is the fine distribution of the moderating material. This fine distribution conserves the very flat power and burnup distribution typical for fast reactor fuel assemblies [10].

Figure 3 provides a general overview on the effect created by the introduction of fine distributed moderating material into the fuel assembly of a sodium-cooled fast reactor on the neutron flux spectrum averaged over the fuel assembly. The neutron spectrum is shown for the whole energy range not only for the standard rage used in fast reactor analysis to better visualize the effect of the moderating material, even if the very low number of neutrons in the thermal energies could cause some uncertainty. The 190group HELIOS 1.9 internal library is used for these spectral curves to get a sufficiently fine resolution in the thermal range. The figure shows a significant difference in energy distribution of the averaged neutron flux after the insertion of the moderating material. In the case with the $\mathrm{ZrH}_{1.6}$ in the wire wrapper a comparably strong "low" energy tail is formed due to the strong moderation effect of the hydrogen atoms 


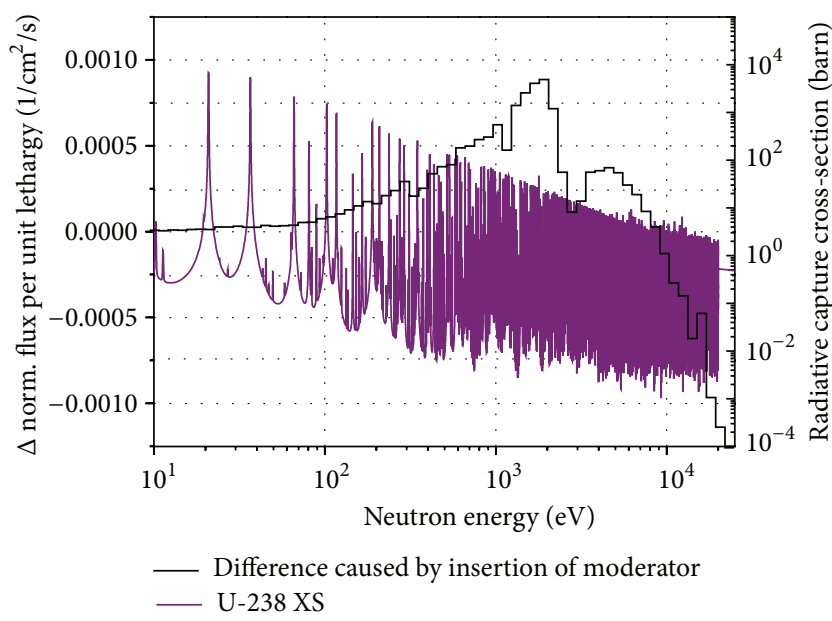

FIgURE 4: Difference in the neutron spectrum caused by the insertion of moderating material calculated with the 190 group library of HELIOS 1.9 and compared to the radiative capture crosssection of uranium-238.

in the metallic compound due to the very efficient moderating material.

The visualization of the change in the neutron spectrum in one figure combined with the radiative capture crosssection of U-238, the major carrier of the absorption in the fast reactor indicates clearly why the Doppler effect caused by the resonance broadening can be enhanced significantly with the proposed insertion of moderating material. Particularly when the following citation is considered. "The Doppler effect in large, fast power reactors occurs almost entirely below about $25 \mathrm{keV}$, because cross-section variations with temperature become very small at higher energies" [1]. This area is the energy span where the resolved resonances of $U$ 238 are shown in Figures 3 and 4.

Particularly in the low energy part of the resonance area, the neutron flux is significantly increased which is highlighted in Figure 4 by the visualized difference caused by the insertion of the moderator. The share of neutrons below $10 \mathrm{keV}$ in the neutron spectrum increases significantly while the share of neutrons above this value decreases due to the moderation. This significant increase leads to a much stronger Doppler effect, since only neutrons which are appearing in the resonance region can be absorbed there. The insertion of the fine distributed moderating material leads to a significant enhancement of the negative feedback effects and to a reduction of the positive feedback effects due to coolant density and temperature. The positive sodium void effect is reduced by $\sim 12 \%$ due to that the insertion of the moderating material, the negative fuel temperature, or Doppler effect is enhanced by $\sim 105 \%$. The positive coolant effect, consisting of the effect caused by the reduced coolant density and the spectral effect due to the coolant temperature change, is reduced by $\sim 10 \%$.

The burnup distribution in the fuel assembly after $100 \mathrm{GWd} / \mathrm{tHM}$ for the reference case and the case with the moderator inside the wire wrapper is given in Figure 5. The burnup in the reference case (left) is characterized by a very flat distribution in the whole assembly as well as over each fuel rod. The reason for this flat distribution lies in the flat power and neutron flux distribution caused by the comparably low total cross-sections of all materials at the dominating neutron energies. The flat power distribution in the fuel assembly is very favorable, since it disburdens the heat removal by the liquid metal sodium coolant. The flat power distribution results in a uniform heatup of the sodium, no hot spots are created, and thus all fuel rods can be operated close to the power limit.

The burnup distribution for case with fine distributed moderating material (Figure 5 bottom) is rather uniform too. A small rim effect appears in each fuel rod due to the resonance self-shielding in the U-238 and the increased number of neutrons in the resonance region caused by the insertion of the moderating material. Additionally, a slightly higher burnup occurs at the pins close to the can wall. Nevertheless, the insertion of fine distributed moderating material, in layers as well as in the wire wrapper, does not create any severe deterioration in the power and burnup distribution in the fuel assembly. This behavior is in strong contrast to the results for the use of moderating material in pins like it has been discussed in several publications. A concentrated introduction of moderating material in special rods causes a significant power and burnup increase in the pins around the moderator pins and a lower burnup in the pins far from the moderator rod. This uneven burnup distributions cause limitations in the obtainable maximal average fuel assembly burnup, since comparably low burnt fuel rods appear in areas far from the moderation pins. Additionally, a very strong power increase at the surface and a rim effect with all follow-up problems appear at the pins next to the moderating pins [10, 11].

Concluding, the use of fine distributed moderating material offers the possibility to enhance the safety characteristics without changing the major operational and design parameters of the fuel assembly like power distribution, fuel configuration and density, geometry, and coolant streaming paths are not changed at all. The idea offers new degrees of freedom for the optimization of the design of the sodium cooled fast reactor core, the cycle strategies and the transmutation potential. The fine distributed moderating material increases the inherent system stability significantly and reduces thus the probability of reaching sodium voiding in a transient. The most interesting point is the possibility of tailoring the feedback coefficients to an ideal value. This value has to be determined from system specific transient and accident analysis, since strong negative feedback is not desired in all accidental scenarios.

On the use of the proposed moderating material $\mathrm{ZrH}$ some comments have to be given. On the one hand, the material is a very efficient moderator, due to the extremely high slowing down power of 1.94, a value in the same range as for light water [22]. On the other hand, $\mathrm{ZrH}$ of $\delta$ or $\varepsilon$ phases does not change the associated volume up to well above $1000^{\circ} \mathrm{C}$, since these phases are in the single-phase region [23]. Thus $\mathrm{ZrH}$ does not show the unpleasant swelling 


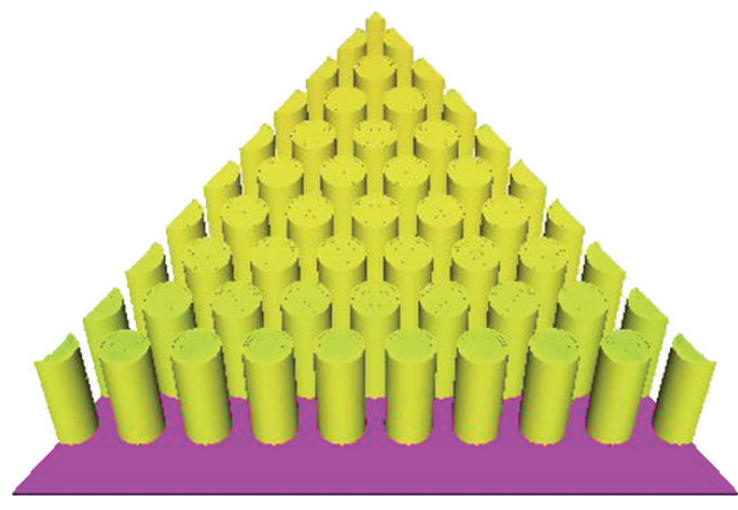

(a)

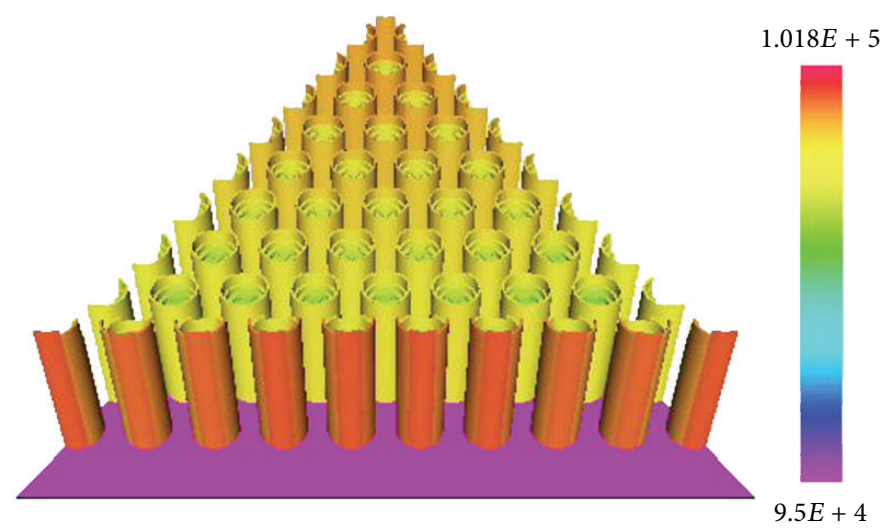

(b)

FiguRE 5: Burnup distribution at $100 \mathrm{GWd} / \mathrm{tHM}$ for the reference case (a) and the case with the moderating material in the wire wrapper (b).

behavior of $\mathrm{UZrH}$ fuel, which Olander et al. describe as swelling due to void formation around the uranium particles and due to fission gas production [24]. These described processes should not appear in pure $\mathrm{ZrH}$ moderator, since both effects are in conjunction with the Uranium component. Nevertheless the equilibrium hydrogen pressure in $\mathrm{ZrH}$ increases strongly at high temperatures which correspond to the sodium voiding temperature $\left(\sim 883^{\circ} \mathrm{C}\right)$ and hydrogen release has to be expected at this temperature level. A significant hydrogen release in accidental conditions $\sim 900^{\circ} \mathrm{C}$ would lead to a strong increase in criticality, thus it would worsen the progression of the accident scenario. This can be explained with the effect of the moderating material on the $k_{\text {inf }}$ (see Figure 10). The insertion of the moderating material leads to a significant reduction of the $k_{\text {inf }}$ back to the value of the reference configuration. This difference would be set free by a complete release of the hydrogen contained in the $\mathrm{ZrH}$ material, and thus the gain of the sodium void reduction will fade away with hydrogen release.

An investigation of the transferability of the reduction of the sodium void effect from the infinite to the finite system has been carried out on an EFR like core configuration [25]. The full core calculations have been performed with the nodal code DYN3d $[26,27]$. The calculation is based on 47 energy group cross-section sets calculated with HELIOS 1.10 using the given geometry models. The full core calculations have shown that the full gain in sodium void reduction demonstrated in the infinite system can be expected to be reached in the finite system too [9]. Thus, a superposition of the new findings in the infinite system and the traditional methods for the sodium void reduction in the finite system like the pancake core shape or a sodium plenum are possible. Additionally, it has to be mentioned that the influence of sodium void reduction inside the fuel assembly using fine distributed moderating material already comes into action when the first sodium bubble appears. In contrast, the traditional methods to reduce the sodium void by increasing the neutron leakage out of the core do not have influence until a significant part of the core is voided.

\section{Possible Moderating Materials}

The key requirement for the moderating material is a high slowing-down power. An efficient moderation with an acceptably small amount of moderating material and a limited number of collisions can only be achieved by a material with high slowing-down power. The limitation of the amount of moderating material is a requirement since the geometric arrangement of the fuel assembly is desired to be untouched as much as possible by the introduction of the moderating material. It has already been demonstrated, that this requirement can only be fulfilled using hydrogen. Other, thermally very stable moderators based on carbon or

${ }^{11}$ boron have been tested, but these materials would require a significantly higher amount of moderating material $[8,9]$. Theoretically pure hydrogen would be a good solution, but it is impossible to confine this material under operation and especially accidental conditions. The same can be stated for liquid bound hydrogen like in water or organic liquids. These materials cause the same problems of confinement in the operational temperature range and during accidents. Particularly with water, the sodium water reaction would be a possible consequence while organic liquids would cause problems with the sodium purity (see oil ingress accidents in SFRs). Thus the focus will be on solid hydrogen-bearing materials. Hydrogen bound in organic compounds, like polyethylene, is thermally not stable enough, but compounds with metals have the possibility for high thermal stability. A literature survey led to the textbook Metal Hydrides by Mueller et al. [22].

Mueller et al. suggest the following criterion for the evaluation of the thermal stability of metal hydrides: "The thermal stability of a reactor component is of utmost importance and in the high-temperature reactors is the prime criterion for the selection of a material. A metal hydride in almost all instances can be expected to dissociate at temperatures well below its melting point or at which its strength is materially reduced. Inasmuch as the degree of dissociation is a function of temperature, the best way to describe the thermal stability 
is to plot isotherms of hydrogen pressure versus the composition of the hydride" [22]. Based on this criterion, a list of possible candidates can be found. Possible materials mentioned in the textbook for forming stable compounds with hydrogen are $\mathrm{Ce}, \mathrm{Zr}, \mathrm{Ca}, \mathrm{Y}, \mathrm{Sc}, \mathrm{Ti}, \mathrm{Th}, \mathrm{V}, \mathrm{Nb}$, and Ta. A more detailed look identifies the materials $\mathrm{V}, \mathrm{Nb}$, and $\mathrm{Ta}$ as not efficient enough for carrying the requested amount of hydrogen. The other materials of the list are possibly interesting candidates. Up to now the reference material has been $\mathrm{ZrH}_{1.6}$ and $\mathrm{ZrH}_{2}$. Based on this reference, Ti can be excluded too, since $\mathrm{Ti}$ is only stable enough until $\sim 600^{\circ} \mathrm{C}$ and thus dissociates earlier than the $\mathrm{Zr}$-based compound. The compounds based on Th and Sc dissociate both about the same temperature range as $\mathrm{ZrH}$, but the achievable hydrogen content is lower than that for $\mathrm{Zr}$.

Based on this reduced matrix of possible materials (Y, Ce, $\mathrm{Ca}$, and $\mathrm{Zr}$ ) for forming the hydrogen-bearing compound a detailed comparison is given in [22]. Figure 6 shows the composition of the hydride represented by the hydrogen number versus dissociation temperature at a hydrogen pressure at 1 atm. The hydrogen number $N_{H}$ which is defined as the number of hydrogen atoms per cubic centimetre of hydride $\cdot 10^{22}$ is

$$
N_{H}=\frac{\rho N_{A}(H / M)}{\text { mol. wt. }} \cdot 10^{-22} \text {, }
$$

where $\rho=$ density of the hydride; $N_{A}=$ Avogadro number; $H / M=$ hydrogen-to-metal atom ration in the hydride; mol. wt. = molecular weight of the hydrogen [22].

It is obvious that $\mathrm{Zr}$ is the most efficient hydrogen carrier at temperatures below $800^{\circ} \mathrm{C}$. The often as moderator for special reactor applications suggested that $\mathrm{ZrH}_{1.6}$ leads to a hydrogen number of

$$
N_{H}\left(\mathrm{ZrH}_{1.6}\right)=\frac{5.61 \cdot 6.022 \cdot 10^{23}(1.6 / 1)}{(91.224+1.6 \cdot 1.0079)} \cdot 10^{-22}=5.82 .
$$

This value leads to a temperature of $\sim 800-850^{\circ} \mathrm{C}$, where the hydrogen release pressure rises above $1 \mathrm{~atm}$. The analysis of Figure 6 shows that all three other materials have a comparable behaviour. There is an area with a stable $N_{H}$ value for a wide temperature range which is followed by a drop in the achievable $N_{H}$ value caused by increasing temperature at the given counter pressure. The major difference is the overall amount of hydrogen which can be bound in the compound. This amount is comparably low for $\mathrm{Ca}$, slightly higher for $\mathrm{Ce}$ and highest for Y. Additionally, the compound based on $\mathrm{Y}$ is the thermally most stable one. The information of this figure can be used for the other direction of the investigation, the choice of the material depending on the required temperature.

When stability up to $1300^{\circ} \mathrm{C}$ is required form reactor transient point of view, Y can carry hydrogen up to an $N_{H}$ value of 3. Reformulating the equation leads to

$$
H=\frac{N_{H} \cdot 10^{22} \cdot M m}{\rho N_{A}-N_{H} \cdot 10^{22} \cdot M h}
$$

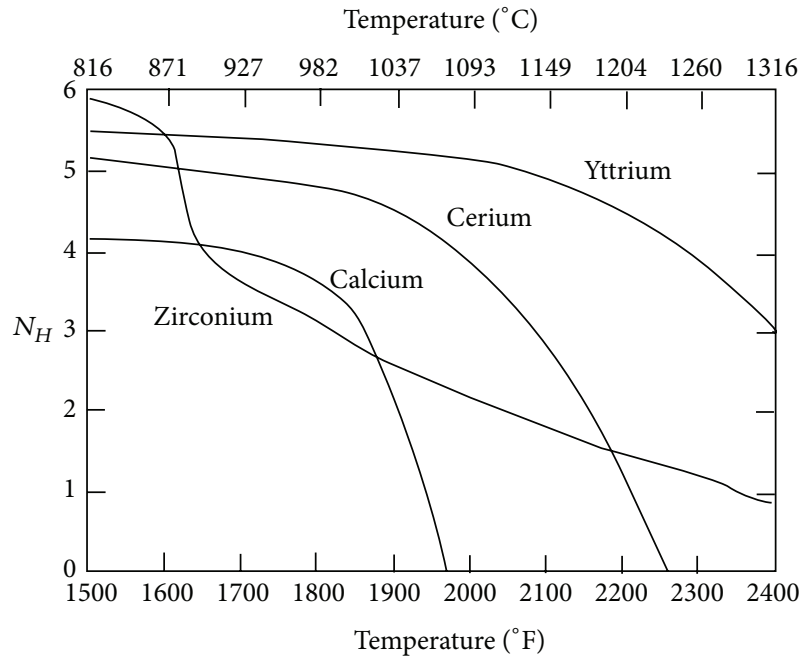

Figure 6: Hydrogen content in metallic $\mathrm{Zr}$, Ce, $\mathrm{Y}$, and $\mathrm{Ca}$ in equilibrium with $1 \mathrm{~atm} \mathrm{H}_{2}$ at various temperatures [28].

and using $N_{H}=3$ leads to the following acceptable configuration:

$$
H\left(\mathrm{YH}_{H}\right)=\frac{3 \cdot 10^{22} \cdot 88.906}{4.3 \cdot 6.022 \cdot 10^{23}-3 \cdot 10^{22} \cdot 1.0079}=1.04 \text {. }
$$

Thus, Yttrium-mono-Hydride will be stable up to more than $1316^{\circ} \mathrm{C}$. A first extrapolation indicates that halving the hydrogen content from $\mathrm{YH}$ to $\mathrm{Y}_{2} \mathrm{H}$ could increase the limit temperature by maximal $\sim 100^{\circ} \mathrm{C}$ more. Using this data it can be stated that a stable hydrogen-bearing compound can be found for the use in an SFR, since the stability can be assured well above the sodium voiding temperature of $\sim 880^{\circ} \mathrm{C}$.

\section{Remarks on Technological Issues and Reactor Experience}

After the choice of the ideal metal for forming the hydrogenbearing compound, the attention will be given to some technological issues. It is very often stated that hydrogen leads to embrittlement of the carrying metal, since hydrogen embrittlement is a well-known and dreaded effect. In contrast to this experience, the following statement is given in [22] on the effect of hydrogen on materials. "It should not be inferred that the presence of hydrogen in metals is always deleterious. When present in amounts less than necessary for embrittlement (this can be as high as $2000 \mathrm{ppm}$ in some zirconium alloys), hydrogen can cause a noticeable increase in strength so long it can be retained in solution. The important point, again, is that hydrogen presents serious problems only when it is not retained in solution or when its concentration exceeds the solubility limits of the alloy so that hydride precipitates or segregation can occur. Otherwise, hydrogen reacts similarly to other alloying elements inmost respects." Other references indicate problems with the hydrogen embrittlement of yttrium. This effect appears 
already for low hydrogen content around and below room temperature [29], and a lack of ductility is described for $\mathrm{YH}_{1.7}$ at temperatures even above the foreseen operation temperature [30]. Another publication gives view on the possibility of cladding the $\mathrm{YH}$ with a protective layer. "Tests at GE-NMPO demonstrated that claddings of Iron-chromium-aluminum and other compositions would successfully protect hydride yttrium in a reactor environment at $600-1050^{\circ} \mathrm{C}$ for test times from 5000 to $10000 \mathrm{~h}$. Posttest microstructures of the hydride were typically crack-free after 50-100 air quenches from operating temperature to ambient temperature" [31]. These tests have been performed for high hydrogen contents$N_{H}>5$. A clear conclusion can be drawn from these varying statements in the literature. Before any application in a fast reactor, the mechanical behavior of the foreseen metal hydride compound has to be tested for the required hydrogen amount and under the planned operational temperature.

Another important technological aspect is the production strategy for the hydrogen-bearing materials, especially for the required wire used for the wire spacers. A description of the ideal strategy is given in [22] too. "Although compacted hydrides can be machined, it is more suitable to hydride massive pre-machined sections. These are much easier to handle and have superior mechanical properties. Hydride alloys provide a range of hydrogen concentrations in combination with considerable variation in nuclear and mechanical properties and good thermal stability. Cladding and canning of the hydrides will prevent severe hydrogen loss at elevated temperatures and maintain structural integrity to some extent."

A comment about a possible coating to prevent hydrogen release even more efficiently is given as final technological remark, once more in [22]. "A number of materials have been investigated as possible barriers to hydrogen migration. Kanigen nickel shows promise as a barrier coating for zirconium hydride of $N_{H}=4$ on the basis of hydrogen loss for times up to $100 \mathrm{~h}$ at $1300^{\circ} \mathrm{F}\left(\mathrm{ca} .700^{\circ} \mathrm{C}\right.$ ) in argon, but it is not suitable at $N_{H}=5$. Oxidation in air and a tendency to crack when the coated hydride was drilled caused Kanigen nickel to be dropped from consideration. ... Preliminary indications where that a modification of an iron $-10 \%$ aluminium $-34 \%$ manganese alloy would meet all requirements of a good coating for yttrium hydride." Thus even on this topic, some historic knowledge is available. Nevertheless, when this kind of materials should be inserted into a nuclear reactor, at least some kind of reactor experience has to be available, or a very comprehensive test program would be required.

There is already some limited experience with $\mathrm{YH}$ in fast reactors. $\mathrm{YH}$ moderators have already been used in the Fast Flux Test Facility (FFTF) for several experimental setups first for tests and then for an isotope production test. "The hydrogen-moderated, Multi-Isotope Production Test Assembly contained isotopic samples to reduce uncertainties in key nuclear data associated with isotope production, and was irradiated in May 1989 in the outer reflector region of the Fast Flux Test Facility." [32] A more detailed description about this experiment indicates the use of $\mathrm{YH}$ moderators. "Yttrium hydride $\left(\mathrm{YH}_{1.7}\right)$ moderator was used to create neutronic environments with intermediate energy levels between thermal systems and fast systems, Six pins containing $\mathrm{YH}_{1.7}$ surrounded the central test pin to provide the required moderated neutron environment. The 12 outer pins contain tungsten up to the elevation of the top of the six central pin test sections, with $\mathrm{YH}_{1.7}$ above the tungsten. Three of the six middle $\mathrm{YH}_{1.7}$ pins contained dosimetry and actinide samples provided and processed." [32]. Before this test some experience has already been available from previous tests. A cobalt test assembly containing $\mathrm{YH}$ pins for neutron moderation was irradiated in the FFTF during cycle 9A for 137.7 equivalent full power days at a power level of $291 \mathrm{MW}$. The assembly contained $19 \mathrm{YH}$ pins and one of the objectives of this test was to provide $\mathrm{YH}$ pins for postirradiation examination to determine the stability of $\mathrm{YH}$ under prototypic operating conditions [33].

The final view in this chapter is for the prices of different nuclear materials, as given in https://www.metal-pages.com/ (status second half 2011):

(i) Y metal \$ 170-210 kg,

(ii) Ce metal \$ 80-170 kg,

(iii) Gd metal \$ 203-226 kg,

(iv) Zr metal \$ 50-250 kg (reactor grade at the upper end).

Thus the prices for yttrium metal are in the usual range for special materials used in nuclear reactors.

\section{Comparison of Enhanced Feedback Effects}

For the use of the yttrium-mono-hydride material the basic investigation to check for eventually appearing differences in the required function of enhancing the feedback effects is given for the neutron spectrum; see Figure 7. The assembly averaged neutron spectrum gives a good overview on the consequences of the insertion of moderating material, even if, like already mentioned, the very low numbers in the thermal energies could have some uncertainties. The 190group HELIOS 1.9 library is used for these spectral curves to get a sufficiently fine resolution in the thermal groups to be able to visualize the effect of the moderating material. The effect of the insertion of the moderating material can be indicated very clearly for $\mathrm{ZrH} 1.6$ as well as for $\mathrm{YH}$. The comparison of the neutron spectrum indicates that the moderation effect is for both materials identical as soon as the identical amounts of hydrogen are inserted into the system. This is assured by using on the one hand a $\mathrm{ZrH}_{1.6}$ wire which is surrounded by a steel shell and on the other hand a full $\mathrm{YH}$ wire.

The comparison of the results for the Zr-based and the Y-based hydrogen-bearing compound, given in Figure 8, indicates only a very minor influence caused by the metallic component of the compound. A detailed comparison of numbers shows that Zr-based material is slightly more efficient, but the difference is very small. It is definitely smaller than the uncertainties in the material data and due to the modelling of the system in the neutron physics code. Thus the Zr-based material can be easily replaced by the Y-based material without influencing the desired effect 


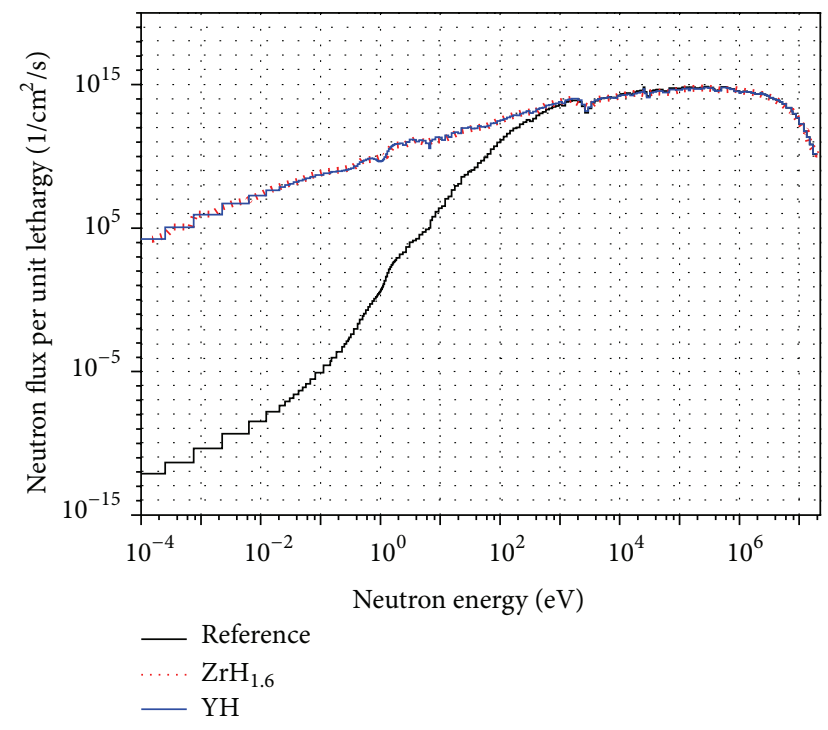

FIGURE 7: Neutron spectrum for the reference fuel assembly and for the fuel assembly with moderating material calculated with the 190group library of HELIOS 1.9.

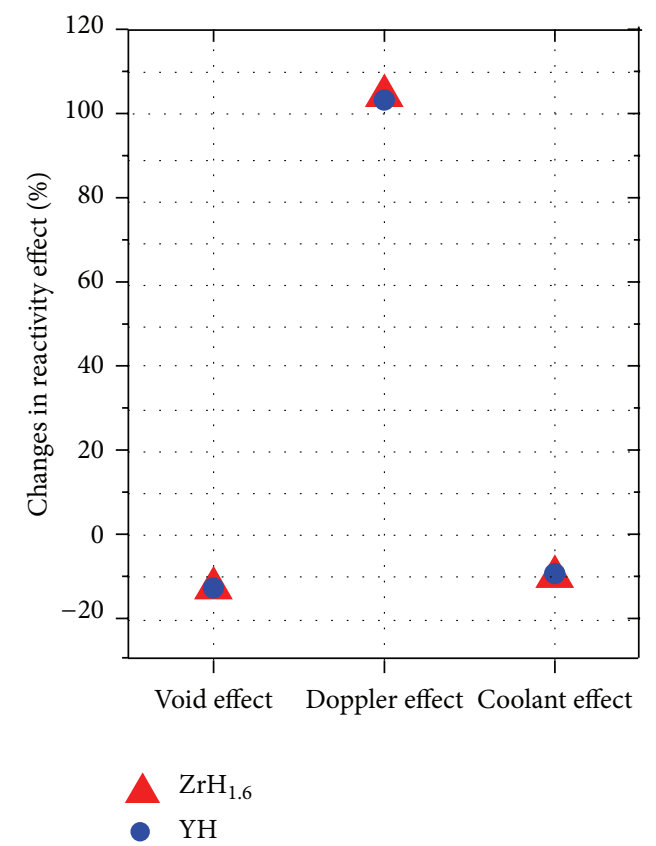

FIGURE 8: Comparison of the influence of the hydrogen-bearing metal compound on the enhancement of the feedback effects.

of enhancing the negative feedback effects and lowering the positive feedback effects in a sodium-cooled fast reactor.

The burnup distribution for the case with distributed moderating material in the wire wrapper (Figure $9 \mathrm{ZrH}$ left and $\mathrm{YH}$ right) is rather uniform, like in the reference solution. A small rim effect appears due to the resonance self-shielding and a slightly higher burnup occurs at the pins close to the can wall. Nevertheless, the insertion of the moderating material in fine distribution, in the wire wrapper, does not create any severe deterioration in the power and burnup distribution, neither for the $\mathrm{ZrH}$ case nor for the $\mathrm{YH}$ case. Thus the burnup distribution confirms the findings for the feedback effects; the change from $\mathrm{ZrH}$ to $\mathrm{YH}$ does not influence the findings of the earlier studies on reducing the sodium void effect and enhancing the negative feedback effects in sodiumcooled fast reactors. The uniform burnup distribution is in strong contrast to the results for the use of moderating material in pins as discussed in several earlier publications and performed in the experiments in the FFTF. Thus this negative effect as demonstrated earlier is very comparable for both moderating materials too. The problem of the power peaking as a consequence of the insertion of moderating material in pins has already been observed in the FFTF tests. "After a survey of methods to introduce hydrogen into an FFTF assembly, Westinghouse Hanford decided to use pins containing yttrium hydride pellets, interspersed with the target pins. It was immediately evident that the hydride assembly had the potential for causing power peaking in the neighboring fuel assemblies because of return low-energy neutrons" [33]. This mentioned significant power increase occurs in the pins around the moderator pin and can easily be observed in the calculation results. The position of the moderator pin is indicated by the empty position (no power production besides $\gamma$ heating). The power production is low in the pins far from the moderator pins. This uneven power distribution will cause implications on the cooling of the fuel element. It leads to increased heatup of the coolant in the channels around the pins with increased power next to the moderator pin. The reason for the power peaks is the higher reaction rate of the slowed down neutrons coming from the moderator pins, since the fission cross-section for the slow neutrons is significantly higher. Additionally, the power peaking will lead to a significant peaking in the bunrup distribution. The consequence is reduced economy. The fuel assemblies have to be operated at a reduced average power density, since the maximum is determined by the peak. On the longer term the average burnup has to be reduced; thus, the fuel residence time is reduced since the maximum burnup will be reached in the peaks much earlier than in the fuel assembly with the flat power and burnup distribution. Thus the use of fine distributed moderating material has less economic drawback than the use of moderator pins.

The evolution of the $k_{\text {inf }}$ over burnup and the accumulation of minor actinides over burnup are given in Figure 10. The insertion of the moderating material reduces the criticality of the fuel assembly. This effect has already been described $[8,9]$. The comparison of the different moderating materials shows that replacing zirconium by yttrium has only a minor effect of the evolution of the $k_{\text {inf }}$ over burnup. The detailed calculation indicated an 80 to $120 \mathrm{pcm}$ higher $k_{\text {inf }}$ for the case using $\mathrm{YH}$. The analysis of the minor actinide accumulation over burnup demonstrates the slightly higher amount for the cases with moderating materials. This effect has already been described too $[8,9]$. The use of $\mathrm{YH}$ leads to a very little reduced minor actinide accumulation, but his value is definitively small compared to the expected uncertainties cause by the nuclear data and the modelling of the fuel assemblies and the burnup chains in the code. 


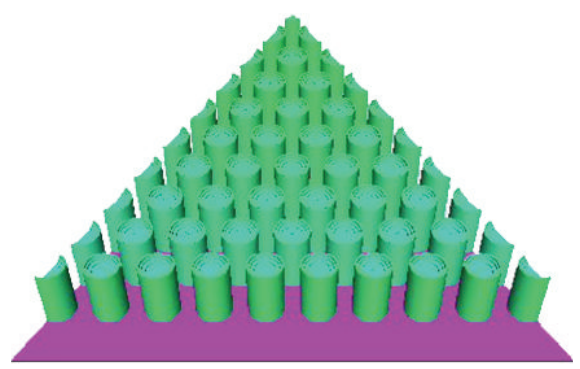

(a)

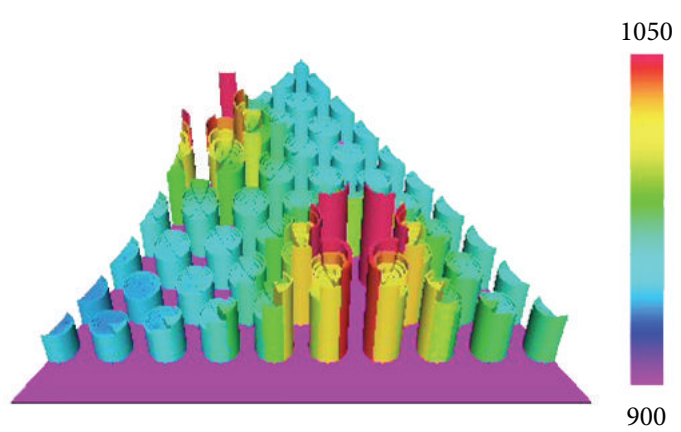

(c)

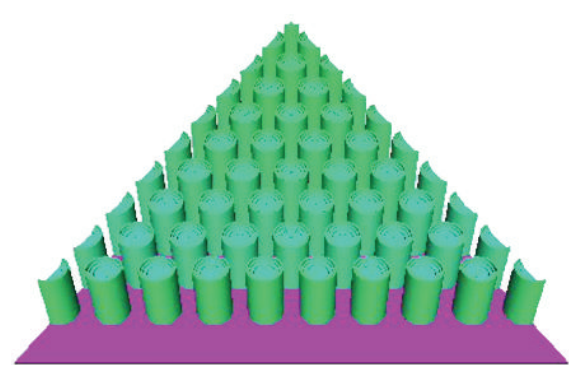

(b)

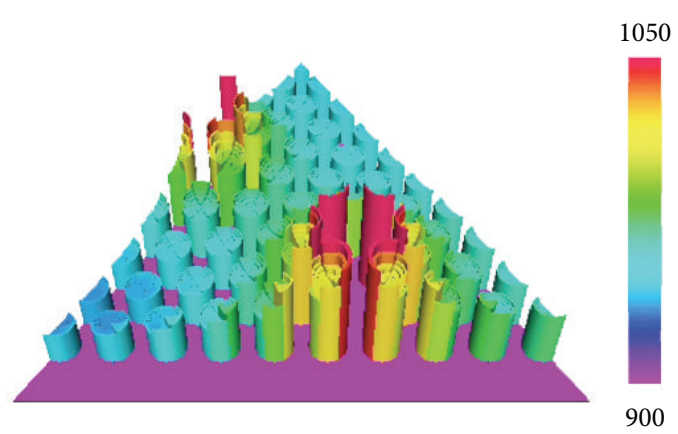

(d)

FIGURE 9: Burnup distribution at $100 \mathrm{GWd} / \mathrm{tHM}$ for the case with the moderating material in the wire wrapper (ZrH-a, YH-b) and for moderator in pins ( $\mathrm{ZrH}-\mathrm{c}, \mathrm{YH}-\mathrm{d})$.

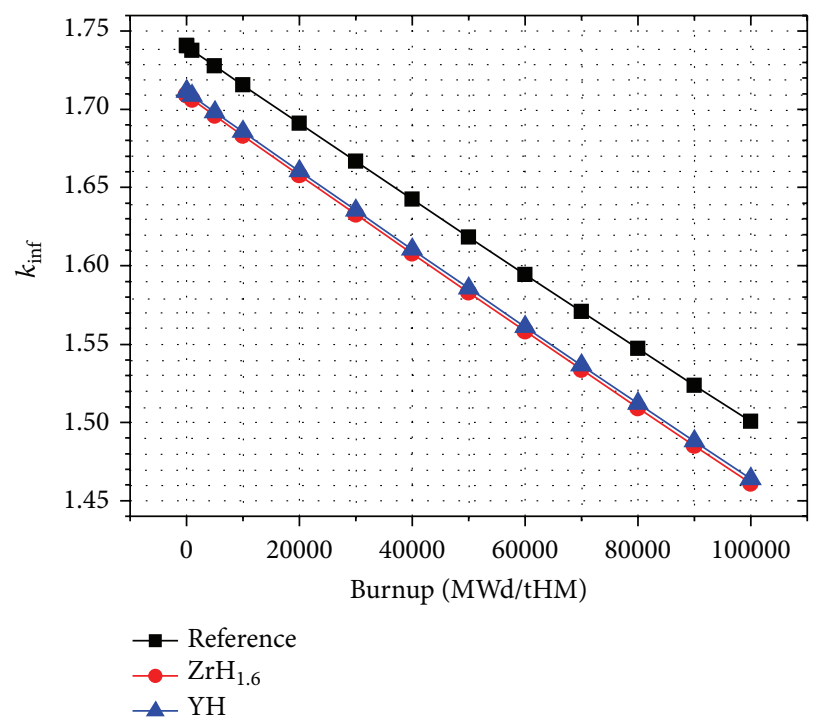

(a)

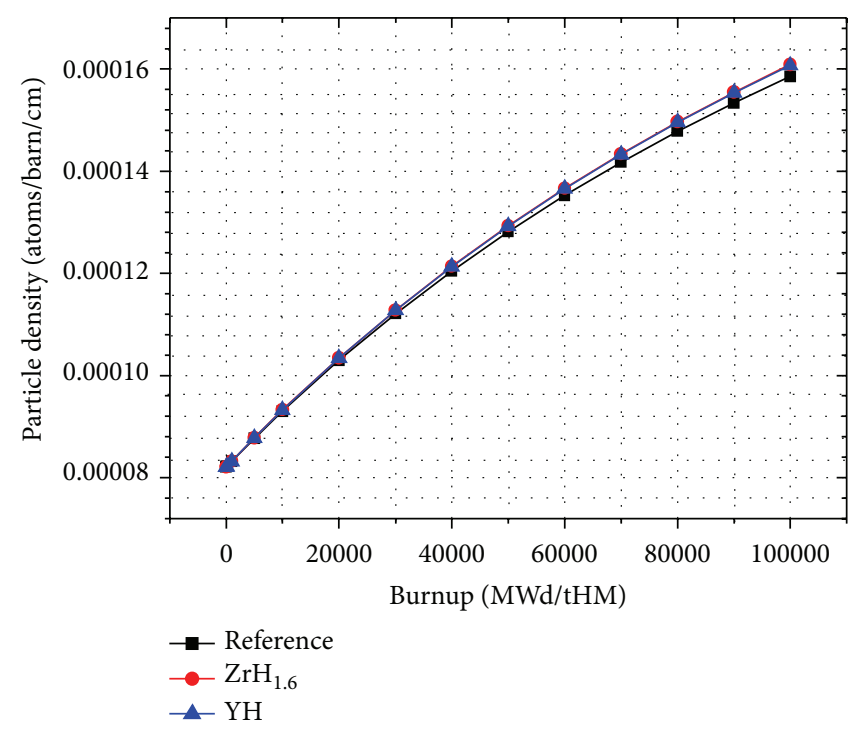

(b)

FIGURE 10: $k_{\text {inf }}$ evolution (left) and minor actinide accumulation (right) for the reference case and the two different moderating materials.

\section{Conclusions}

The use of fine distributed moderating material offers the possibility to enhance the safety characteristics of sodium cooled fast reactors without changing the major operational and design parameters. Fuel assembly power density and distribution, fuel configuration and density, fuel assembly geometry, and coolant streaming paths are not changed at all.
The idea offers new degrees of freedom for the optimization of the design of the sodium-cooled fast reactor core, the cycle strategies, and the transmutation potential. The fine distributed moderating material increases the inherent system stability significantly and reduces thus the probability of reaching sodium voiding in a transient. The most interesting point is the possibility of tailoring the feedback coefficients to an ideal value, which has to be determined 
from system-specific transient and accident analysis, since strong negative feedback is not desired in all accidental scenarios.

Up to now, a major limitation and a point of critics were the use of $\mathrm{ZrH}$-based moderators, since the thermal stability cannot be reliably assured up to the temperature of the onset of sodium voiding; dissociation rises sharply around $880^{\circ} \mathrm{C}$ and sodium voiding starts around $883^{\circ} \mathrm{C}$. Thus the dissociation cannot be avoided safely during a transient and the dissociation followed by a loss of hydrogen would definitively worsen the transient. In this publication it has been shown that the replacement of the metallic part of the compound can lead to significantly increased thermal stability, especially when the hydrogen number is reduced. The use of yttrium is very promising, since with this material a compound can be formed which is stable up to more than $1300^{\circ} \mathrm{C}$-yttrium-mono-hydride. The literature review gives confidence that this kind of material can be produced and handled. However, some historic data indicate that fabrication and mechanical tests for the special material with the required hydrogen content will be necessary, especially to clarify the mechanical stability. Additionally, there is already some reactor experience from the use in experiments in the Fast Flux Test Facility (FFTF). The comparison of the effect on the neutron spectrum, the influence on the feedback effects, and the burnup distribution demonstrate that there is no major difference between the use of $\mathrm{ZrH}$ and $\mathrm{YH}$ as long as the overall hydrogen content is identical. The analysis of the $k_{\text {inf }}$ evolution and the minor actinide accumulation shows only very minor influence by the different moderating materials. All results together give confidence that the results of the previous studies based on $\mathrm{ZrH}$ can be transferred to the case using $\mathrm{YH}$ as moderating material. Thus $\mathrm{YH}$ is identified as the ideal material for the implementation of the idea of using fine distributed material for the enhancement of negative feedback effects in sodium-cooled fast reactors, since the major limitation of the use of $\mathrm{ZrH}$ can be eliminated without influencing the desired effects.

\section{Conflict of Interests}

The author declares that there is no conflict of interests regarding the publication of this paper.

\section{References}

[1] "IAEA TM on Innovative Fast Reactor Designs with Enhanced Negative Reactivity Feedback Features," IAEA Headquarters, Vienna, Austria, 2012, http://www.iaea.org/NuclearPower/Meetings/2012/2012-02-27-02-29-TM-NPTD.html.

[2] R. N. Hill and H. Khalil, "Evaluation of LMR design options for reduction of sodium void worth," in Proceedings of the International Conference on Physics of Reactors, vol. 1, pp. 11-19, Marseille, France, 1990.

[3] G. Rimpault, L. Buiron, P. Sciora, and F. Varaine, "Towards GEN IV SFR design: promising ideas for large advanced SFR core designs," in Proceedings of the International Conference on the Physics of Reactors (PHYSOR '08), pp. 2394-2400, Bern, Switzerland, September 2008.
[4] L. Buiron, P. Dufour, G. Rimpault et al., "Innovative core design for generation IV sodium-cooled fast reactors," in Proceedings of the International Conference on Advances in Nuclear Power Plants (ICAPP '07), Nice, France, May 2007.

[5] K. Sun, J. Krepel, K. Mikityuk, and R. Chawla, "A neutronics study for improving the safety and performance parameters of a 3600 MWth sodium-cooled fast reactor," Annals of Nuclear Energy, vol. 53, pp. 464-475, 2013.

[6] A. Rineiski, B. Vezzoni, D. Zhang, X.-N. Chen, F. Gabrielli, and M. Marchetti, "Sodium void effect reduction and minor actinide incineration in ESFR," Transactions of the American Nuclear Society, vol. 104, pp. 720-721, 2011.

[7] M. S. Chenaud, N. Devictor, G. Mignot et al., "Status of the astrid core at the end of the pre-conceptual design," in Proceedings of the International Conference on Fast Reactors and Related Fuel Cycles: Safe Technologies and Sustainable Scenarios (FR13), Paris, France, March 2013.

[8] B. Merk, S. Kliem, E. Fridman, and F. P. Weiß, "On the use of zirconium based moderators to enhance the feedback coefficients in a MOX fuelled sodium cooled fast reactor," Nuclear Science and Engineering, vol. 171, no. 2, pp. 136-149, 2012.

[9] B. Merk, E. Fridman, and F. P. Weiß, “On the use of a moderation layer to improve the safety behavior in sodium cooled fast reactors," Annals of Nuclear Energy, vol. 38, no. 5, pp. 921-929, 2011.

[10] B. Merk and F.-P. Weiß, "Analysis of the influence of different arrangements for $\mathrm{ZrH}$ moderator material on the performance of a SFR core," Annals of Nuclear Energy, vol. 38, no. 11, pp. 2374$2385,2011$.

[11] B. Merk and F. P. Weiß, "On the effect of different placing $\mathrm{ZrH}$ moderator material on the performance of a SFR core," in Proceedings of the Advances in Reactor, Physics-Linking Research, Industry, and Education, Knoxville, Tenn, USA, April 2012.

[12] B. Merk and F. P. Weiß, “On the use of moderating material to enhance the feedback coefficients in SFR cores with high minor actinide content," in Proceedings of the International Conference of Applied Psychology (ICAPP '12), Paper 12428, Chicago, Ill, USA, June 2012.

[13] B. Merk, "Moderating material to compensate the drawback of high minor actinide containing transmutation fuel on the feedback effects in SFR cores," Science and Technology of Nuclear Installations, vol. 2013, Article ID 172518, 10 pages, 2013.

[14] B. Merk, "On the use of fine distributed moderating material to enhance feedback coefficients in fast reactors," in Proceedings of the IAEA TM on Innovative Fast Reactor Designs with Enhanced Negative Reactivity Feedback Features, Vienna, Austria, February 2012.

[15] E. A. Villarino, R. J. J. Stamm'ler, A. A. Ferri, and J. J. Casal, "HELIOS: angularly dependent collision probabilities," Nuclear Science and Engineering, vol. 112, no. 1, pp. 16-31, 1992.

[16] R. Sanchez, J. Mondot, Z. Stankovski, A. Cossic, and I. Zmijarevic, "APOLLO II: a user-oriented, portable, modular code for multigroup transport assembly calculations," Nuclear Science and Engineering, vol. 100, no. 3, pp. 352-362, 1988.

[17] IAEA Fast Reactor Database-2006 Update, http://www.iaea .org/nuclearenergy/nuclearknowledge/.

[18] A. E. Waltar and A. B. Reynolds, Fast Breeder Reactors, Pergamon Press, New York, NY, USA, 1981. 
[19] A. Pay, E. Francillon, B. Steinmetz, D. Barnes, and N. Meda, "European Fast Reactor (EFR) fuel element design," in Proceedings of the 10th International Conference on Structural Mechanics in Reactor Technology, Anaheim, Calif, USA, 1989.

[20] HELIOS Methods, Studsvik Scandpower, Waltham, Mass, USA, 2003.

[21] R. Rachamin, C. Wemple, and E. Fridman, "Neutronic analysis of SFR core with HELIOS-2, SERPENT, and DYN3D codes," Annals of Nuclear Energy, vol. 55, pp. 194-204, 2013.

[22] W. M. Mueller, J. P. Blackledge, and G. G. Libowitz, Metal Hydrides, Academic Press, New York, NY, USA, 1968.

[23] K. Tsujimoto, T. Iwasaki, N. Hirakawa, T. Osugi, S. Okajima, and M. Andoh, "Improvement of reactivity coefficients of metallic fuel LMFBR by adding moderating material," Annals of Nuclear Energy, vol. 28, no. 9, pp. 831-855, 2001.

[24] D. Olander, E. Greenspan, H. D. Garkisch, and B. Petrovic, "Uranium-zirconium hydride fuel properties," Nuclear Engineering and Design, vol. 239, no. 8, pp. 1406-1424, 2009.

[25] J. C. Lefèvre, C. H. Mitchell, and G. Hubert, "European fast reactor design," Nuclear Engineering and Design, vol. 162, no. 23, pp. 133-143, 1996.

[26] U. Rohde, U. Grundmann, and S. Kliem, "DYN3D—advanced reactor simulations in 3D," Nuclear Energy Review, vol. 2, pp. 28-30, 2007.

[27] C. Beckert and U. Grundmann, "A nodal expansion method for solving the multigroup SP3 equations in the reactor code DYN3D," in Proceedings of the Joint International Topical Meeting on Mathematics and Computations and Supercomputing in Nuclear Applications (MむC+SNA '07), Monterey, Calif, USA, April 2007.

[28] E. S. Funston, "Physical properties of yttrium hydride," in Nuclear Metallurgy, A Symposium on Metallic Moderators and Cladding Materials, American Institute of Mining and Metallurgical Engineers, New York, NY, USA, 1960.

[29] C. V. Owen and T. E. Scott, "Hydrogen embrittlement of yttrium," Journal of the Less-Common Metals, vol. 90, no. 2, pp. 275-282, 1983.

[30] J. B. Vetrano, "Hydrides as neutron moderator and reflector materials," Nuclear Engineering and Design, vol. 14, no. 3, pp. 390-412, 1971.

[31] R. van Houten, "Selected engineering and fabrication aspects of nuclear metal hydrides (Li, Ti, Zr, and Y)," Nuclear Engineering and Design, vol. 31, no. 3, pp. 434-448, 1974.

[32] D. W. Wootan, J. A. Caggiano, L. L. Carter, D. P. Jordheim, and A. H. Lu, "Isotope production test in the fast flux test facility," in Proceedings LMR: A Decade of LMR Progress and Promise, Washington, DC, USA, November 1990, American Nuclear Society, La Grange Park, Ill, USA, 1990.

[33] D. W. Wootan, J. A. Rawlins, L. L. Carter, H. R. Brager, and R. E. Schenter, "Analysis and results of a hydrogen-moderated isotope production assembly in the fast flux test facility," Nuclear Science and Engineering, vol. 103, no. 2, pp. 150-156, 1989. 


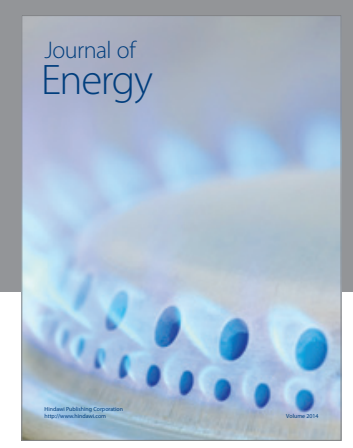

Journal of

Industrial Engineering
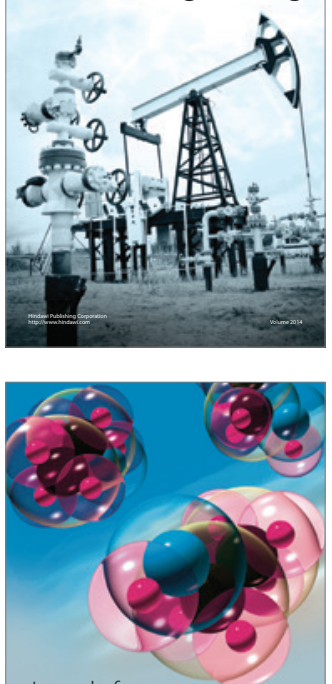

Fuels
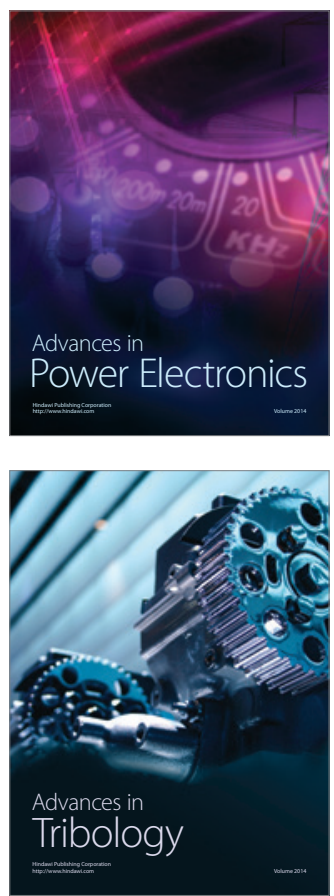

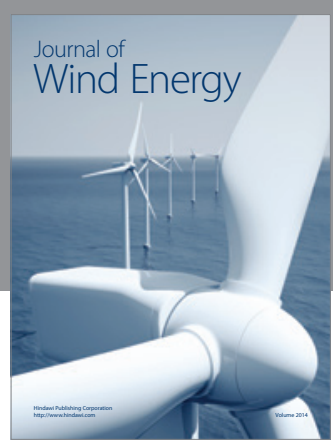

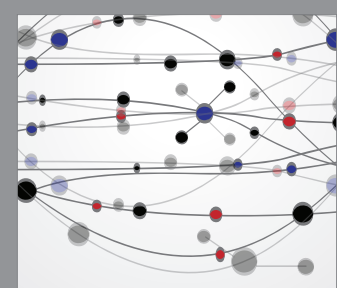

The Scientific World Journal

Submit your manuscripts at http://www.hindawi.com

Journal of

Structures
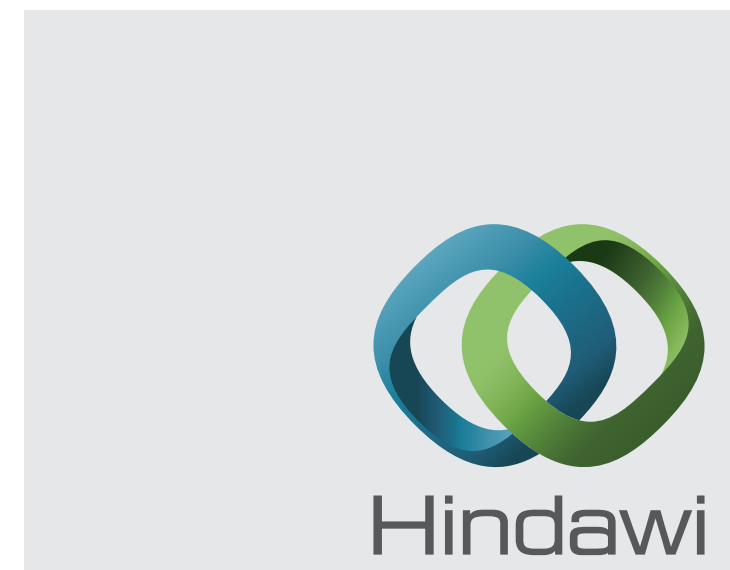

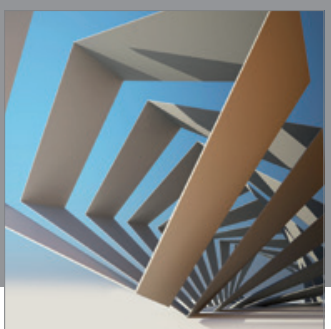

Rotating

Machinery
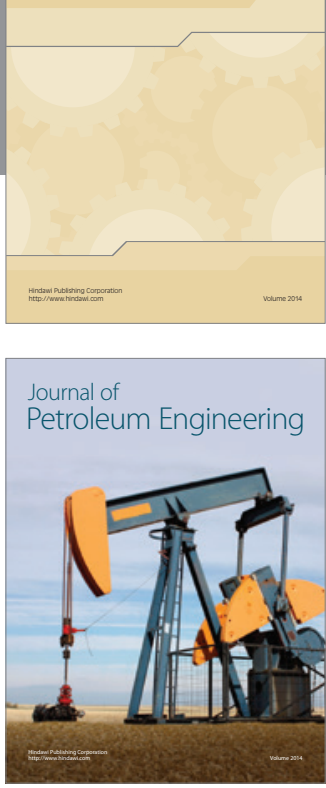

Journal of

Solar Energy
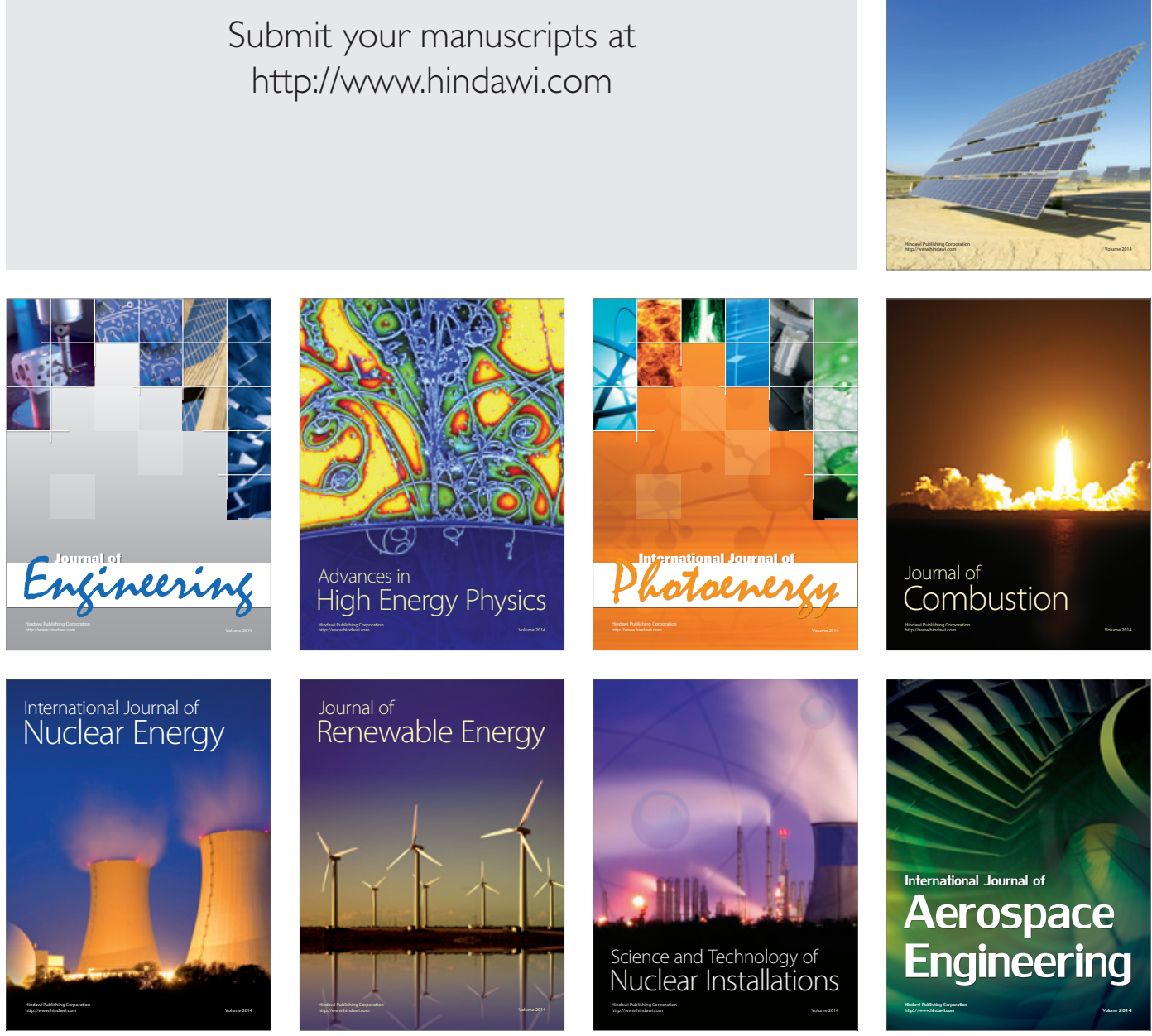